\title{
Feasibility of the intravascular lithotripsy in coronary artery disease. Short-term outcomes of the Lower-Silesia Shockwave Registry
}

\author{
Piotr Rola',2, Adrian Włodarczak', Jan Jakub Kulczycki', Mateusz Barycki², Łukasz Furtan', Marek Szudrowicz', \\ Artur Jastrzębski', Maciej Pęcherzewski', Adrian Doroszko ${ }^{3}$, Maciej Lesiak ${ }^{4}$
}

'Department of Cardiology, The Copper Health Centre, Lubin, Poland

2Department of Cardiology, Provincial Specialized Hospital in Legnica, Legnica, Poland

${ }^{3}$ Department of Internal Medicine, Hypertension and Clinical Oncology, Wroclaw Medical University, Wrocław, Poland

${ }^{4} 1^{\text {st }}$ Department of Cardiology, Poznan University of Medical Sciences, Poznań, Poland

\author{
Correspondence to: \\ Piotr Rola, MD, PhD, \\ Department of Cardiology \\ Provincial Specialized \\ Hospital in Legnica, \\ Iwaszkiewicza 5 \\ 59-220 Legnica, Poland, \\ phone: +48 888272007 , \\ e-mail: \\ piotr.rola@gmail.com \\ Copyright by the Author(s), \\ 2021 \\ Kardiol Pol. 2021; \\ 79 (10): 1133-1135; \\ DOI: 10.33963/KP.a2021.0093 \\ Received: \\ May 23, 2021 \\ Revision accepted: \\ August 20, 2021 \\ Published online: \\ August 20, 2021
}

\section{INTRODUCTION}

The presence of calcified lesions has a substantial impact on percutaneous coronary intervention ( $\mathrm{PCl}$ ) outcomes. The severity of calcifications impairs stent crossing and correlates with a higher rate of periprocedural complications including vessel dissection or perforation, acute or chronic in-stent thrombosis as well as in-stent restenosis. A response to these unfavorable clinical events is aggressive plaque modification prior to coronary stent implantation.

Numerous strategies aiming at the appropriate preparation of calcified plaques have been implemented [1]. The two main techniques include the balloon-depended and the atherectomy devices. Even though they remain an essential part of contemporary practice, all of them have some limitations [2]. To overcome them, a new balloon-based coronary system for IVL - Shockwave C2 Intravascular Lithotripsy (S-IVL) (Shockwave Medical Inc, Santa Clara, CA, USA) has been introduced. It is a novel method of calcified plaque modification, which transforms electrical energy into mechanical one, leading to calcium nodules defragmentation. In this brief report, we present the short-term outcomes of the S-IVL registry - the Lower-Silesia Shockwave Registry (LSSR).

\section{METHODS}

We retrospectively enrolled patients from the two cooperating Cardiac Departments in the Lower Silesia Region with a clinical indication for $\mathrm{PCl}$, where due to a presence of "undilatable" lesion, advanced plaque modification methods were needed. Undilatable lesion was defined as a lesion after unsuccessful high-pressure inflation (20\% diameter at least $18 \mathrm{~atm}$ ) of a non-compliant (NC) balloon catheter (sized 1:1 to the reference vessel diameter balloon), with or without prior plaque preparation with smaller NC balloon or rotational atherectomy (RA).

There were no angiographic exclusion criteria regarding lesion anatomy, such as the length, tortuosity, severity, or prior stent placement. Angiography was used to determine the appropriate number of pulses and the size of the S-IVL catheter for optimal vessel preparation. Subsequent stent implantation and percutaneous coronary intervention optimization (including the use of intravascular imaging) were performed at the discretion of the operator.

The study had two primary endpoints: clinical success and safety outcomes. Clinical success was defined as an effective stent deployment or optimization of the previously implanted not fully expanded stent (with less than $<20 \%$ in-stent residual stenosis) and the presence of Thrombolysis in Myocardial Infarction (TIMI) 3 flow at the end of the procedure.

Safety outcomes were defined as the absence of procedural complications (coronary perforation, slow- or no-reflow, new coronary thrombus, ventricular arrhythmias, vessel closure), and device failure (inability to cross the lesion, malfunction, or rapture). Also, major adverse cardiac and cerebrovascular events (MACCE) were recorded. MACCE was defined as acute coronary syndrome, cerebrovascular events, major bleeding, need for repeated re- 
vascularization, or death. Clinical follow-up was obtained by telephone 30-day after the index procedure (additional 6- and 12-month follow-up is ongoing and will be reported when completed).

The study was based on retrospective registry data. No ethics committee approval nor patient consent was required.

\section{Statistical analysis}

The data is presented as the mean with the standard deviation (SD) or the median with the interquartile range (IQR), dependent on the normality of distribution, assessed previously using the Shapiro-Wilk test, as appropriate. All calculations were made with the $\mathrm{R}$ language.

\section{RESULTS AND DISCUSSION}

From May 2019 to January 2021, we enrolled 52 patients (54 treated lesions) - 35 males and 17 females with an average age of 71.2 (7.3) years with a high prevalence of cardiovascular risk factors and comorbidities (hypertension $90.3 \%$, hypercholesterolemia $96.1 \%$, diabetes mellitus $57.7 \%)$. Most S-IVL procedures were performed in acute coronary syndrome (ACS) settings (82.7\%) - mainly at the time of the index $\mathrm{PCl}$. Forty-one procedures were related to lesions that had not undergone prior coronary angioplasty, the remaining 13 concerned in-stent restenosis due to significant stent under-expansion. The majority (69.2\%) of these cases were treated with additional prolonged inflation of the drug-eluting balloon (DEB) - the rest (4 out of $13-30.8 \%$ ) required additional DES implantation due to the operator's decision. Table 1 provides the details on the clinical, procedural, and postprocedural characteristics.

The median SYNTAX score was 11 (7-24) points. In six cases, before S-IVL, a rotational atherectomy was performed as a part of lesion preparation. The average S-IVL balloon catheter size was $3.3(0.4)$ and a median of 40 (30-80) sonic pulses was delivered. Hospital observation revealed three procedure-related complications. In the first case, the patient developed a ventricular arrhythmia during the procedure, which was interrupted by ALS and electrical defibrillation. The second case was related to the rupture of the S-IVL balloon after 30 pulses. In the third case, we observed failure of S-IVL therapy — residual stenosis of more than $50 \%$ - after 100 sonic pulses. This patient was qualified for coronary artery bypass grafting. One stroke was recognized during the index hospitalization. Two major bleedings in the postprocedural period were recorded. The first patient required transfusion of 6 units of packed red blood cells for gastrointestinal bleeding. The second patient required transfusion of 2 units of packed red blood cells due to vascular access complications. No other MACCE were recorded for 30 days after hospital discharge.

Artery calcification remains one of the greatest challenges in the management of coronary artery disease. Armamentarium for optimal lesion preparation includes the pre-dilation with NC or ultrahigh-pressure balloons, utilization of scoring or cutting balloons, and RA devic-
Table 1. Clinical, procedural, and postprocedural characteristics of the study population

\begin{tabular}{|c|c|}
\hline & Overall $(n=52)$ \\
\hline Age, mean (SD) & $71.2(7.3)$ \\
\hline Male, n (\%) & $35(67.3)$ \\
\hline \multicolumn{2}{|l|}{ Diagnosis } \\
\hline Stable angina, $\mathrm{n}(\%)$ & $9(17.3)$ \\
\hline Unstable angina, $\mathrm{n}(\%)$ & $2(3.8)$ \\
\hline NSTEMI, n (\%) & $38(73.0)$ \\
\hline STEMI, n (\%) & $3(5.9)$ \\
\hline Hypercholesterolemia, n (\%) & $50(96.1)$ \\
\hline Diabetes, n (\%) & $29(55.7)$ \\
\hline Hypertension, $\mathrm{n}(\%)$ & $47(90.3)$ \\
\hline Kidney failure, $\mathrm{n}(\%)$ & $10(19.2)$ \\
\hline Post PCI status, n (\%) & $35(67.3)$ \\
\hline Primary diagnosis Ml, $\mathrm{n}(\%)$ & $28(53.8)$ \\
\hline Syntax score, median (IQR) & $11(7-24)$ \\
\hline LVEF, \%, mean (SD) & $52.3(13.8)$ \\
\hline Treated vessel & $10(19.2)$ \\
\hline LM, n (\%) & $18(34.6)$ \\
\hline LAD, n (\%) & $6(11.6)$ \\
\hline$C x, n(\%) R C A, n(\%)$ & $18(34.6)$ \\
\hline Primary lesion, $\mathrm{n}(\%)$ & $41(78.8)$ \\
\hline Stent underexpansion, $\mathrm{n}(\%)$ & $13(25)$ \\
\hline СTO lesions, $n(\%)$ & $5(9.6)$ \\
\hline Primary rotablation, $\mathrm{n}(\%)$ & $6(11.5)$ \\
\hline Previously predilatation, $\mathrm{n}(\%)$ & $43(82.6)$ \\
\hline Predilatation pressure, atm, mean (SD) & $19.8(4.2)$ \\
\hline Initial diameter stenosis, \%, mean (SD) & $83.3(9.7)$ \\
\hline Final diameter stenosis, \%, median (IQR) & $5(0-14)$ \\
\hline IVL diameter, mm, mean (SD) & $3.3(0.4)$ \\
\hline Number of pulses, median (IQR) & $40(30-80)$ \\
\hline Postdilatation, $\mathrm{n}(\%)$ & $49(94.2)$ \\
\hline Postdilatation pressure, atm, mean (SD) & $18.5(5.0)$ \\
\hline Number of DES per procedure, mean (SD) & $1.4(0.3)$ \\
\hline Total DES length per procedure, median (IQR) & $38(26-71)$ \\
\hline Number of DEB inflation, $n(\%)$ & $9(17.3)$ \\
\hline OCT/IVUS guided PCI, n (\%) & $11(21.2)$ \\
\hline Clinical success, n (\%) & $51(98.1)$ \\
\hline Radial access, n (\%) & $48(88.8)$ \\
\hline Femoral access, $\mathrm{n}(\%)$ & $6(12.2)$ \\
\hline $6 \mathrm{~F}$ guide catheter, $\mathrm{n}(\%)$ & $32(59.2)$ \\
\hline $7 \mathrm{~F}$ guide catheter, $\mathrm{n}(\%)$ & $22(40.8)$ \\
\hline Radiation doses, mGy, median (IQR) & $1334(699-2105)$ \\
\hline Contrast amount, ml, median (IQR) & $180(135-230)$ \\
\hline In-hospital MACCE, n (\%) & $3(5.7)$ \\
\hline 30-days after procedure MACCE, $n(\%)$ & $3(5.7)$ \\
\hline
\end{tabular}

Abbreviations: CTO, chronic total occlusion; $C x$, circumflex artery; DEB, drug eluting balloon; DES, drug eluting stent; IVL, intravascular lithotripsy; IVUS, intravascular ultrasound; MACCE, major adverse cardiac and cerebrovascular events; LAD, left anterior descending; LM, left main; LVEF, left ventricular ejection fraction; NSTEMI, no ST-elevation myocardial infraction; OCT, optical coherence tomography; RCA right coronary artery; STEMI, ST-elevation myocardial infraction

es. Success rates using these strategies are high and reach over $90.0 \%[3,4]$. Nevertheless, some limitations are still observed. In the presence of eccentric calcium, the dilation force of the balloon is limited and may be redirected to less resistant, noncalcified parts of the vessel. Rotational devices perform atheroablation by sanding/abrasion, resulting in pulverization of the superficial plaque. However, the deep calcifications may remain untouched [5]. S-IVL could respond to the aforementioned superficial mech- 
anisms of plaque modification. It generates sonic pulses that propagate through the lesion and selectively interact even with profound calcified plaques. The efficiency and safety of S-IVL were initially confirmed in a Disrupt II study [6]. Although preliminary data are encouraging $[7,8]$, convincing clinical evidence from randomized trials is missing.

We obtained a higher clinical success rate, in comparison to the previously described ( $98.1 \%$ vs. $84.6 \%-95.0 \%)$ $[7,8]$. This finding might be related to the simultaneous use of RA and S-IVL (6 cases) in the most challenging lesions. Rota-lithotripsy is a novel bail-out strategy used for resistant lesions. Only a few case reports [9-11] regarding this method are available. A high rate of clinical success was maintained despite the relatively high prevalence of patients with under-expansion of previously implanted stents in our registry ( $25.0 \%$ vs. $21.7 \%$ ) [7]. A clinical success rate in these non-option patients is overall lower $(64.7 \%$ vs. $87.1 \%)[7,8,12]$. The severity of coronary artery disease (median of SYNTAX score, 11) with coexisting complexity of $\mathrm{PCI}$ procedures (5 CTO, 6 Rota-lithotripsies) included in the LSSR led to the relatively high average use of contrast volume (median of $180 \mathrm{ml}$ ) and radiation dose (median of $1334 \mathrm{mGy}$ ). These findings are partially consistent with previously reported data $[7,8,12]$

Preliminary safety outcomes are also encouraging. We observed one balloon ruptured during treatment without any sequelae, as well as one episode of ventricular arrhythmias probably connected to ongoing ischemia induced by ACS (high-risk patient with NSTEMI and multivessel disease-accumulated SYNTAX score, 33.5). However, in view of the reports suggesting that S-IVL can induce ventricular arrhythmias [13], future studies are necessary. Probably due to the high prevalence of trans-radial access (88.8\%) with accompanying predominance of $6 \mathrm{~F}$ guiding catheter (59.2\%), we observed only one access-related bleeding in this high-risk group. These data might suggest that wider use of S-IVL may reduce the number of complex PCI performed with femoral access and decrease the rate of access points complications [14].

Retrospectively the data collected from the LSSR suggest intravascular lithotripsy is relatively safe and effective as a method of modifying calcified plaque in short-term observation, especially when performed via radial access. Moreover, subsequent studies are needed to evaluate the long-term results.

\section{Article information}

Conflict of interest: None declared.

Open access: This article is available in open access under Creative Common Attribution-Non-Commercial-No Derivatives 4.0 International (CC BY-NC-ND 4.0) license, allowing to download articles and share them with others as long as they credit the authors and the publisher, but without permission to change them in any way or use them commercially. For commercial use, please contact the journal office at kardiologiapolska@ptkardio.pl.

How to cite: Rola P, Włodarczak A, Kulczycki JJ, et al. Feasibility of the intravascular lithotripsy in coronary artery disease. Short-term outcomes of the Lower-Silesia Shockwave Registry. Kardiol Pol. 2021; 79(10): 1133-1135, doi: 10.33963/KP.a2021.0093.

\section{REFERENCES}

1. Perfetti $M$, Fulgenzi $F$, Radico $F$, et al. Calcific lesion preparation for coronary bifurcation stenting. Cardiol J. 2019; 26(5): 429-437, doi: 10.5603/CJ.a2019.0094, indexed in Pubmed: 31565792.

2. McQuillan C, Jackson MWP, Brilakis ES, et al. Uncrossable and undilatable lesions. A practical approach to optimizing outcomes in $\mathrm{PCl}$. Catheter Cardiovasc Interv. 2021; 97(1): 121-126, doi: 10.1002/ccd.29001, indexed in Pubmed: 32453918.

3. Gaul G, Viertl N, Austin PC, et al. Low-speed rotational atherectomy with substantial debulking and long-term survival: a retrospective observational study of 889 consecutive patients. Kardiol Pol. 2019; 77(4):451-457, doi: 10.5603/KP.a2019.0035, indexed in Pubmed: 30835326.

4. Correction to: High-Speed Rotational Atherectomy Versus Modified Balloons Before Drug-Eluting Stent Implantation in Severely Calcified Coronary Lesions: The Randomized PREPARE-CALC Trial. Circ Cardiovasc Interv. 2018; 11(10): e000040, doi: 10.1161/HCV.0000000000000040, indexed in Pubmed: 30354641

5. Tomey MI, Kini AS, Sharma SK. Current status of rotational atherectomy. JACC Cardiovasc Interv. 2014; 7(4): 345-353, doi: 10.1016/j. jcin.2013.12.196, indexed in Pubmed: 24630879.

6. Ali ZA, Nef H, Escaned J, et al. Safety and effectiveness of coronary intravascular lithotripsy for treatment of severely calcified coronary stenoses: the disrupt CAD II study. Circ Cardiovasc Interv. 2019; 12(10): e008434, doi: 10.1161/CIRCINTERVENTIONS.119.008434, indexed in Pubmed:31553205.

7. Aksoy A, Salazar C, Becher MU, et al. Intravascular lithotripsy in calcified coronary lesions: a prospective, observational, multicenter registry. Circ Cardiovasc Interv. 2019; 12(11): e008154, doi: 10.1161/CIRCINTERVENTIONS.119.008154, indexed in Pubmed: 31707803.

8. Brinton TJ, Ali ZA, Hill JM, et al. Feasibility of shockwave coronary intravascular lithotripsy for the treatment of calcified coronary stenoses. Circulation. 2019; 139(6): 834-836, doi: 10.1161/CIRCULATIONAHA.118.036531, indexed in Pubmed: 30715944.

9. Włodarczak A, Kulczycki J, Furtan $Ł$, et al. Rotational atherectomy and intravascular lithotripsy: two methods versus a single lesion. Kardiol Pol. 2021; 79(6): 712-713, doi: 10.33963/KP.15962, indexed in Pubmed: 33890748.

10. Jurado-Román A, Gonzálvez A, Galeote G, et al. RotaTripsy: combination of rotational atherectomy and intravascular lithotripsy for the treatment of severely calcified lesions. JACC Cardiovasc Interv. 2019; 12(15): e127-e129, doi: 10.1016/j.jcin.2019.03.036, indexed in Pubmed: 31326422.

11. Włodarczak A, Rola P, Barycki M, et al. Rota-Lithotripsy-A novel bail-out strategy for calcified coronary lesions in acute coronary syndrome. The first-in-man experience.J Jlin Med. 2021;10(9), doi: 10.3390/jcm10091872, indexed in Pubmed: 33925916.

12. Ielasi A, Moscarella $E$, Testa $L$, et al. IntravaScular lithotripsy for the management of undilatable coronary stent: the SMILE registry. Cardiovasc Revasc Med. 2020; 21(12): 1555-1559, doi: 10.1016/j.carrev.2020.05.020, indexed in Pubmed: 32580881.

13. Karimi Galougahi K, Patel S, Shlofmitz RA, et al. Calcific plaque modification by acoustic shock waves: intravascular lithotripsy in coronary interventions. Circ Cardiovasc Interv. 2021; 14(1):e009354, doi: 10.1161/CIRCINTERVENTIONS.120.009354, indexed in Pubmed: 32907343.

14. Kolkailah AA, Alreshq RS, Muhammed AM, et al. Transradial versus transfemoral approach for diagnostic coronary angiography and percutaneous coronary intervention in people with coronary artery disease. Cochrane Database Syst Rev. 2018; 4: CD012318, doi: 10.1002/14651858.CD012318. pub2, indexed in Pubmed: 29665617. 